\title{
APPLICATION OF AN AGGREGATION TECHNIQUE TO FACILITY LAYOUT DESIGN SELECTION
}

\author{
Serkan Altuntas ${ }^{1^{*}}$, Turkay Dereli ${ }^{2}$ \\ Keywords: Facility layout, Facility design, Facility location
}

\begin{abstract}
Facility layout in manufacturing and service systems affects the productivity and efficiency of the systems. Generally, more than one appropriate location is available based on associations among facilities. This leads to alternative facility layout designs. It is not an easy activity to select the best facility layout design among alternatives for facility engineers and decision makers. Many number of ranking of alternative facility layout designs can be generated by the use of different approaches. However, rankings obtained from these approaches do not suggest unique ranking. In this study, an aggregation technique is conducted to sort facility layout design alternatives generated by multiple conventional approaches. It is mainly based on a linear programming model. The results of this study show that alternative facility layout designs can be easily ranked in descending order by the aggregation technique.
\end{abstract}

\section{INTRODUCTION}

Facility layout problem basically deals with the question of where m numbers of facilities (machines) are arranged within a given location [1]. Location of facilities in a layout is quite significant because of its direct effect on some important indicators such as material flow distance, total product produced, cycle time, waiting time, facility utilization, etc [2]. There are two main aims of most production facilities, namely (1) minimization of the manufacturing costs and (2) increasing the diversity and quality of products [3]. A good facility layout provides these two superiorities simultaneously. Investors face facility layout problem at the beginning of the construction of factory. This is one of the main problem that should be solved initially for future manufacturing success. Therefore, appropriate or optimal solution of facility layout problem is quite important for productivity and efficiency in a manufacturing system.

Facility layout design selection is also quite important problem for facility engineers. The facility engineers in industry design alternative facility layouts because of the presence of more than one alternative appropriate location for facilities. There may be more than one alternative appropriate location even if you conduct a single approach for facility layout problem. In addition, there are multi-criteria, effecting facility layout design and composed of qualitative criteria and quantitative criteria [4]. This leads to generation of alternative layout designs. It is necessary to consider alternative layout designs to achieve a good facility layout in a manufacturing process. Therefore, a systematic and scientific method should be used to evaluate alternative layout designs and rank them in descending order.

Too many efforts have been performed in the literature for the solution of the facility layout problem (see Singh and Sharma, 2006). Among them, a genetic algorithm [5-6], simulated annealing-based algorithm [7], weighted Euclidean distance based approach [8], fuzzy weighted association rules [9], artificial immune system [10], clonal selection algorithm [11-12] and nonlinear programming model and AHP [13] have been proposed in the literature for facility layout problem. Most of these approaches are based on heuristic approaches to find out an acceptable solution. Some of these heuristic approaches can also provide optimal solution. Furthermore, mathematical approaches are also used to find optimum and exact solution for facility layout problems (e.g., [14]). Simulation is performed to evaluate facility layouts in the literature as well (e.g., [15]). Details on facility layout problem can be found in review studies (e.g., [16-22]). The aim of the proposed approaches in the literature is basically to minimize the total cost and material flow distance in the system. However, alternative facility layout designs are usually obtained from the use of the different approaches even if the aim of the approaches are the same in practice. Generally, the facility engineers suggest alternative facility layout designs to decision makers

This paper was recommended for publication in revised form by Regional Editor Tolga Taner

${ }^{1}$ Department of Industrial Engineering, Yildiz Technical University, Istanbul, Turkey

*E-mail address: serkan@yildiz.edu.tr (Corresponding author)

${ }^{2}$ Office of the President, Iskenderun Technical University, Iskenderun, Turkey

${ }^{2}$ Department of Industrial Engineering, Gaziantep University, Gaziantep, Turkey 
due to the presence of more than one alternative location obtained by different approaches. The facility engineers should select the best facility layout designs in case of alternatives. Hence, this study uses an aggregation technique for facility layout design selection. The aggregation technique, which is mainly based on a linear programming model, was proposed by Jahan et al. [23] for optimal decision making in materials selection.

Material selection is a multi-criteria decision making problems in the literature and include a number of alternatives and some criteria. In material selection problem, there are a number of alternative and criteria which are important for material selection. The aim of these problems to rank alternatives in descending order with respect to the criteria and select the best alternative for decision maker. However, the rank obtained by the use of different multiple conventional approaches are different for material selection. This fact are also true for all multi-criteria decision making problems. The aggregation technique uses the results of the multiple conventional approaches to find a unique ranking and propose the best one among alternatives. The proposed aggregation technique can be very well adapted to other multi-criteria decision making problems as well. In this study, the technique is conducted to sort facility layout design alternatives generated by multiple conventional approaches in the literature.

There are various studies that rank alternative facility layout designs for decision makers in practice. Sharma and Singhal [24] proposed a procedural approach and used simulation to evaluate 5 alternative facility layout designs. Attri and Grover [25] utilized preference selection index method for facility layout design selection problem including four alternatives and five criteria. Kuo et al. [26] conducted grey relational analysis to assess 18 alternative layouts with respect to 6 performance attributes. Yang and Hung [27] conducted TOPSIS and fuzzy TOPSIS methods to rank 18 alternative layouts with respect to 6 performance attributes as well. Maniya and Bhatt [28] and Yang and Kuo [29] proposed preference selection index and DEA methods, respectively for the evaluation of the facility layout design selection problem. In this study the same problem which was solved by [26-29] is considered by the aggregation technique.

\section{THE AGGREGATION TECHNIQUE FOR OPTIMAL DECISION-MAKING}

The aggregation technique used in this paper was proposed by Jahan et al. [23]. They applied this technique to material selection. The technique is appropriate to rank the facility layout design alternatives in the presence of inconsistency in the ranking results obtained by multiple conventional approaches such as the technique for order preference by similarity to ideal solution (TOPSIS), the fuzzy TOPSIS, AHP, analytical hierarchical process (AHP) etc. Figure 2 illustrates the position of the aggregation technique in the material selection process. As can be seen from Figure 2, at least two ranking results obtained from different approaches are required to conduct the aggregation technique. It should be also noted that there should be inconsistency in the ranking results obtained from the approaches. The figure can be easily adapted to facility layout design selection process. Because, the aggregation technique used in this study can be easily adapted to other selection problem having inconsistency in the ranking results obtained from multiple conventional approaches. There are many aggregation techniques proposed in the literature. However, the aggregation technique used in this study is very appropriate for facility layout design selection due to the fact that material selection problem is similar to the facility layout design selection problem. As it was stated in introduction section, both material selection and facility layout design selection problems are multi-criteria selection problem. Therefore, in this study, the aggregation technique proposed for the material selection process is used to sort facility layout design selection.

The aggregation technique is introduced in stepwise manner based on [23] as follows.

Step 1: Use a ranking matrix as a ( $m \times m$ dimensional).

$\mathrm{m}$ shows the number of alternatives.

Mik presents the number of times each alternative $\mathrm{i}$ assigns to the kth ranking.

Step 2: Calculate Cik which is Mik $+\mathrm{Ci}, \mathrm{k} 1 \mathrm{i}, \mathrm{k}=1, \ldots \& \mathrm{Ci}, 0=0$

Step 3: Solve the following linear programming problem to rank the alternatives.

$\operatorname{Max} \sum_{i=1}^{m} \sum_{k=1}^{m} C_{i k} * W_{k} * N_{i k}$

where, 


$$
W_{k}=\frac{m^{2}}{k}
$$

Subject to

$$
\begin{aligned}
& \sum_{k=1}^{m} N_{i k}=1 \quad i=1,2,3, \ldots, m \\
& \sum_{i=1}^{m} N_{i k}=1 \quad k=1,2,3, \ldots, m \\
& N_{i k}=\left\{\begin{array}{l}
0 \\
1
\end{array} \text { for all } i \text { and } k\right.
\end{aligned}
$$

As can be seen from above simple linear programming (LP), the aim of the objective function is to maximize the weighting for top rankings. Basically, this LP can be solved in LINGO software or it can be solved by using the simplex algorithm to find out ranking of alternative facility layout design alternatives.

\section{RESULTS AND DISCUSSION}

Application of the aggregation technique to facility layout design selection is conducted by using an example taken from the literature. The example is taken from Yang and Kuo [29] and it consists of 18 facility layout design alternatives. The example includes 10 departments having unequal size for a packaging company. Departments name and size are given in Table 1. Figure 1 illustrates these facility layout designs. Alternative 18 presents the existing layout design. These alternative layout designs were generated based on qualitative criteria and quantitative criteria (distance (m), adjacency, shape ratio, flexibility, accessibility and maintenance). Details on these criteria can be found in Yang and Kuo [29]. Table 2 shows the ranking order of 18 facility layout designs by different methods, namely Preference Selection Index-PSI [28], Grey Relational Analysis-GRA [26], Technique for Order Preference by Similarity to Ideal Solution-TOPSIS [27], Fuzzy TOPSIS [27], and Data Envelopment Analysis-DEA [29]. These methods are extensively used in the literature for multi-criteria decision making problems and each one has different calculation process. For example, the TOPSIS method considers crisp value to rank alternatives while the Fuzzy TOPSIS uses linguistic expressions for ranking. Furthermore, alternative facility layouts are considered as decision making units in DEA. In addition, the reciprocal values of distance and shape ratio are taken as the DMU outputs. As can be seen from Table 2, there are 5 ranking obtained from different methods and there is inconsistency in the ranking results. Although alternative 11 and alternative 15 are ranked first and second respectively by both the TOPSIS method and the Fuzzy TOPSIS methods. The remaining alternatives are ranked differently by these methods. Therefore, the problem is appropriate for the application of the aggregation technique introduced in the previous section.

In Step 1, a ranking as a $(m x m$ dimensional $\times)$ is constructed based on Table 2 . Number of times facility layout designs assigned to different ranks $\left(\mathrm{M}_{\mathrm{ik}}\right)$ is given in Table 3 . In step 2, Table 4 is constructed to present $\mathrm{C}_{\mathrm{ik}}$ values to be used for linear programming. The following Linear Programming (LP) model based on the aggregation technique is solved in MATLAB environment to find optimal ranking of facility layout design alternatives. Ranking obtained by the aggregation technique are given in Table 5. One can easily see from Table 5, the ranking is not the same as the ranking obtained from multiple conventional approaches proposed in the literature. Herein, the aggregation technique can be considered as data fusion method. Comparison of ranking order of facility layout design alternatives are illustrated in Figure 3. 


$$
\begin{aligned}
& \operatorname{Max} Z \sum_{i=1}^{18} \sum_{k=1}^{18} C_{i k} * \frac{18^{2}}{k} * N_{i k} \\
& =0 * \frac{18^{2}}{1} * N_{11}+0 * \frac{18^{2}}{2} * N_{12}+0 * \frac{18^{2}}{3} * N_{13}+0 * \frac{18^{2}}{4} * N_{14}+0 * \frac{18^{2}}{5} * N_{15}+0 * \frac{18^{2}}{6} \\
& * N_{16}+0 * \frac{18^{2}}{7} * N_{17}+0 * \frac{18^{2}}{8} * N_{18}+0 * \frac{18^{2}}{9} * N_{19}+2 * \frac{18^{2}}{10} * N_{110}+2 * \frac{18^{2}}{11} * N_{111}+2 \\
& * \frac{18^{2}}{12} * N_{112}+3 * \frac{18^{2}}{13} * N_{113}+3 * \frac{18^{2}}{14} * N_{114}+4 * \frac{18^{2}}{15} * N_{115}+5 * \frac{18^{2}}{16} * N_{116}+5 * \frac{18^{2}}{17} \\
& * N_{117}+5 * \frac{18^{2}}{18} * N_{118}+\sum_{i=2}^{18} \sum_{k=1}^{18} C_{i k} * \frac{18^{2}}{k} * N_{i k} \\
& \sum_{k=1}^{18} N_{i k}=1 \quad i=1,2,3, \ldots, 18 \\
& \sum_{i=1}^{m 18} N_{i k}=1 \quad k=1,2,3, \ldots, 18 \\
& N_{i k}=\left\{\begin{array}{l}
0 \\
1
\end{array} \text { for all } i \text { and } k\right.
\end{aligned}
$$

Table 1 Departments name and size [29]

\begin{tabular}{|l|l|l|}
\hline No. & Department name & Size $\left(\mathrm{m}^{2}\right)$ \\
\hline 1 & Wafer sawing & 89.21 \\
\hline 2 & Die bond & 181.51 \\
\hline 3 & Wire bond & 577.38 \\
\hline 4 & Molding & 599.57 \\
\hline 5 & Dejunk/trimming and curing & 183.71 \\
\hline 6 & Electro deflash/solder platting & 500.13 \\
\hline 7 & Marking & 199.94 \\
\hline 8 & Forming and singulation & 186.40 \\
\hline 9 & Lead scanning/inspection & 110.78 \\
\hline 10 & Packaging & 51.09 \\
\hline
\end{tabular}


Table 2 Ranking order of facility layout designs by different methods.

\begin{tabular}{|l|l|l|l|l|l|}
\hline & PSI [28] & GRA [26] & TOPSIS [27] & Fuzzy TOPSIS [27] & DEA [29] \\
\hline A1 & 15 & 10 & 16 & 13 & 10 \\
\hline A2 & 9 & 8 & 9 & 9 & 4 \\
\hline A3 & 16 & 15 & 10 & 14 & 15 \\
\hline A4 & 11 & 11 & 4 & 4 & 11 \\
\hline A5 & 17 & 13 & 12 & 12 & 14 \\
\hline A6 & 18 & 16 & 6 & 16 & 6 \\
\hline A7 & 10 & 17 & 18 & 17 & 18 \\
\hline A8 & 6 & 7 & 13 & 6 & 7 \\
\hline A9 & 5 & 5 & 15 & 11 & 8 \\
\hline A10 & 13 & 9 & 3 & 7 & 12 \\
\hline A11 & 3 & 3 & 1 & 1 & 1 \\
\hline A12 & 14 & 18 & 17 & 15 & 17 \\
\hline A13 & 12 & 14 & 14 & 18 & 16 \\
\hline A14 & 8 & 12 & 5 & 8 & 13 \\
\hline A15 & 1 & 1 & 2 & 2 & 1 \\
\hline A16 & 7 & 6 & 8 & 10 & 5 \\
\hline A17 & 2 & 2 & 7 & 5 & 9 \\
\hline A18 & 4 & 4 & 11 & 3 & 1 \\
\hline
\end{tabular}

Table 3 Number of times facility layout designs assigned to different ranks $\left(\mathrm{M}_{\mathrm{ik}}\right)$

\begin{tabular}{|l|r|r|r|r|r|r|r|r|r|r|r|r|r|r|r|r|r|r|r|}
\hline & & 1 & 2 & 3 & 4 & 5 & 6 & 7 & 8 & 9 & 10 & 11 & 12 & 13 & 14 & 15 & 16 & 17 & 18 \\
\hline A1 & & & & & & & & & & & 2 & & & 1 & & 1 & 1 & & \\
\hline A2 & & & & & 1 & & & & 1 & 3 & & & & & & & & & \\
\hline A3 & & & & & & & & & & 1 & & & & 1 & 2 & 1 & & \\
\hline A4 & & & & 2 & & & & & & & 3 & & & & & & & \\
\hline A5 & & & & & & & & & & & & 2 & 1 & 1 & & & 1 & \\
\hline A6 & & & & & & 2 & & & & & & & & & & 2 & & 1 \\
\hline A7 & & & & & & & & & & & 1 & & & & & & & 2 & 2 \\
\hline A8 & & & & & & & 2 & 2 & & & & & & 1 & & & & & \\
\hline A9 & & & & & & 2 & & & 1 & & & 1 & & & & & & & \\
\hline A10 & & & & 1 & & & & 1 & & 1 & & & 1 & 1 & & & & & \\
\hline A11 & & 3 & & 2 & & & & & & & & & & & & & & & \\
\hline A12 & & & & & & & & & & & & & & & 1 & 1 & & 2 & 1 \\
\hline A13 & & & & & & & & & & & & & 1 & & 2 & & & & 1 \\
\hline A14 & & & & & & 1 & & & 2 & & & & 1 & 1 & & & & & \\
\hline A15 & & 3 & 2 & & & & & & & & & & & & & & & & \\
\hline A16 & & & & & 1 & 1 & 1 & 1 & & 1 & & & & & & & & \\
\hline A17 & & & 2 & & 1 & & 1 & & 1 & & & & & & & & \\
\hline A18 & & 1 & 1 & 2 & & & & & & 1 & & & & & & \\
\hline
\end{tabular}




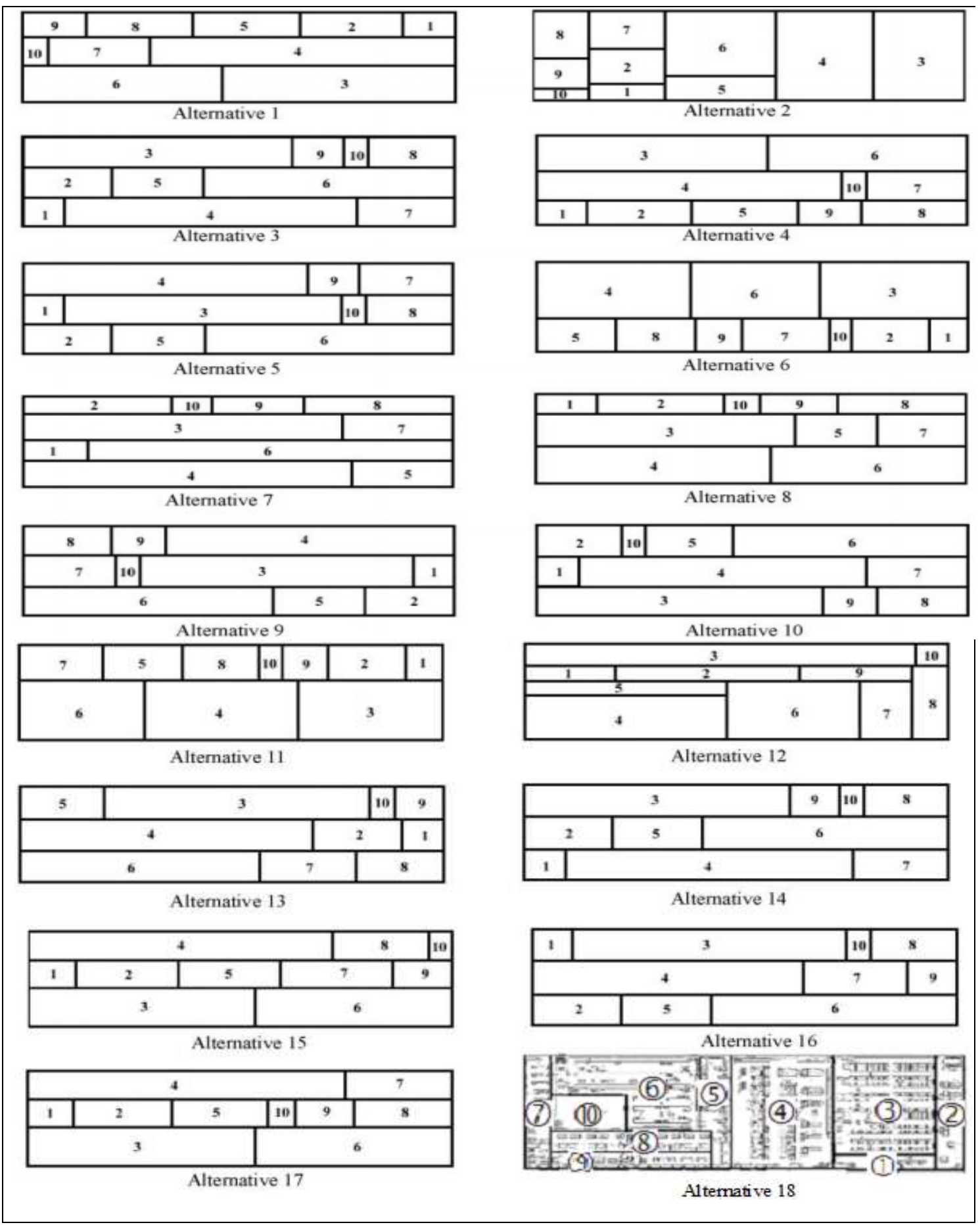

Figure 1. Alternative facility layout designs [29] 
Table 4 Smoothing of facility layout assignment over ranks $\left(\mathrm{C}_{\mathrm{ik}}\right)$

\begin{tabular}{|l|r|r|r|r|r|r|r|r|r|r|r|r|r|r|r|r|r|r|}
\hline & 1 & 2 & 3 & 4 & 5 & 6 & 7 & 8 & 9 & 10 & 11 & 12 & 13 & 14 & 15 & 16 & 17 & 18 \\
\hline A1 & 0 & 0 & 0 & 0 & 0 & 0 & 0 & 0 & 0 & 2 & 2 & 2 & 3 & 3 & 4 & 5 & 5 & 5 \\
\hline A2 & 0 & 0 & 0 & 1 & 1 & 1 & 1 & 2 & 5 & 5 & 5 & 5 & 5 & 5 & 5 & 5 & 5 & 5 \\
\hline A3 & 0 & 0 & 0 & 0 & 0 & 0 & 0 & 0 & 0 & 1 & 1 & 1 & 1 & 2 & 4 & 5 & 5 & 5 \\
\hline A4 & 0 & 0 & 0 & 2 & 2 & 2 & 2 & 2 & 2 & 2 & 5 & 5 & 5 & 5 & 5 & 5 & 5 & 5 \\
\hline A5 & 0 & 0 & 0 & 0 & 0 & 0 & 0 & 0 & 0 & 0 & 0 & 2 & 3 & 4 & 4 & 4 & 5 & 5 \\
\hline A6 & 0 & 0 & 0 & 0 & 0 & 2 & 2 & 2 & 2 & 2 & 2 & 2 & 2 & 2 & 2 & 4 & 4 & 5 \\
\hline A7 & 0 & 0 & 0 & 0 & 0 & 0 & 0 & 0 & 0 & 1 & 1 & 1 & 1 & 1 & 1 & 1 & 3 & 5 \\
\hline A8 & 0 & 0 & 0 & 0 & 0 & 2 & 4 & 4 & 4 & 4 & 4 & 4 & 5 & 5 & 5 & 5 & 5 & 5 \\
\hline A9 & 0 & 0 & 0 & 0 & 2 & 2 & 2 & 3 & 3 & 3 & 4 & 4 & 4 & 4 & 5 & 5 & 5 & 5 \\
\hline A10 & 0 & 0 & 1 & 1 & 1 & 1 & 2 & 2 & 3 & 3 & 3 & 4 & 5 & 5 & 5 & 5 & 5 & 5 \\
\hline A11 & 3 & 3 & 5 & 5 & 5 & 5 & 5 & 5 & 5 & 5 & 5 & 5 & 5 & 5 & 5 & 5 & 5 & 5 \\
\hline A12 & 0 & 0 & 0 & 0 & 0 & 0 & 0 & 0 & 0 & 0 & 0 & 0 & 0 & 1 & 2 & 2 & 4 & 5 \\
\hline A13 & 0 & 0 & 0 & 0 & 0 & 0 & 0 & 0 & 0 & 0 & 0 & 1 & 1 & 3 & 3 & 4 & 4 & 5 \\
\hline A14 & 0 & 0 & 0 & 0 & 1 & 1 & 1 & 3 & 3 & 3 & 3 & 4 & 5 & 5 & 5 & 5 & 5 & 5 \\
\hline A15 & 3 & 5 & 5 & 5 & 5 & 5 & 5 & 5 & 5 & 5 & 5 & 5 & 5 & 5 & 5 & 5 & 5 & 5 \\
\hline A16 & 0 & 0 & 0 & 0 & 1 & 2 & 3 & 4 & 4 & 5 & 5 & 5 & 5 & 5 & 5 & 5 & 5 & 5 \\
\hline A17 & 0 & 2 & 2 & 2 & 3 & 3 & 4 & 4 & 5 & 5 & 5 & 5 & 5 & 5 & 5 & 5 & 5 & 5 \\
\hline A18 & 1 & 1 & 2 & 4 & 4 & 4 & 4 & 4 & 4 & 4 & 5 & 5 & 5 & 5 & 5 & 5 & 5 & 5 \\
\hline
\end{tabular}

Table 5 Ranking obtained by the aggregation technique

\begin{tabular}{|l|c|c|c|c|c|c|c|c|c|c|c|c|c|c|c|c|c|c|}
\hline $\begin{array}{l}\text { Layout } \\
\text { design }\end{array}$ & A1 & A2 & A3 & A4 & A5 & A6 & A7 & A8 & A9 & A10 & A11 & A12 & A13 & A14 & A15 & A16 & A17 & A18 \\
\hline Rank & 13 & 9 & 15 & 11 & 14 & 6 & 18 & 7 & 5 & 12 & 1 & 17 & 16 & 8 & 2 & 10 & 3 & 4 \\
\hline
\end{tabular}

Although the ranking for the some alternative layout designs are the same in Figure 3, overall ranking result obtained from the aggregation technique is different from the previous rankings obtained from the multiple conventional approaches. This is actually expected result that is not the same with the multiple conventional approaches. Because, it uses the results of all the multiple conventional approaches as inputs. It aggregates these results in the calculation process to rank alternatives.

\section{CONCLUSION}

Facility layout design is one of most important design problem for decision makers in manufacturing and service systems. Selection of the best alternative layout design increase some significant performance indicators such as productivity and efficiency in the system. Therefore, facility engineers should select the best layout design among the alternatives to decrease the manufacturing costs. In this study, an example including 18 facility layout design alternatives was conducted to show how the aggregation technique works in practice. The example has been ranked previously by 5 different methods, namely PSI, GRA, TOPSIS, Fuzzy TOPSIS and DEA in the literature. The aggregation technique has a simple calculation process and therefore it can be easily conducted in practice. Unlike most of the multiple conventional approaches, the aggregation technique doesn't require knowledge of experts. Herein, alternative layout designs were sorted by this technique. The results of this study show that facility layout design alternatives can be ranked by the use of the aggregation technique. In the future research, other multiple conventional approaches such as Analytical Network Process (ANP) can be utilized and then the aggregation technique can be used to test the sensitivity of the technique. In addition, more than one example taken from different industries can be performed to test the viability of the aggregation technique in the future. 
Journal of Thermal Engineering, Technical Note, Vol. 3, No. 1, pp. 1078-1088, January, 2017

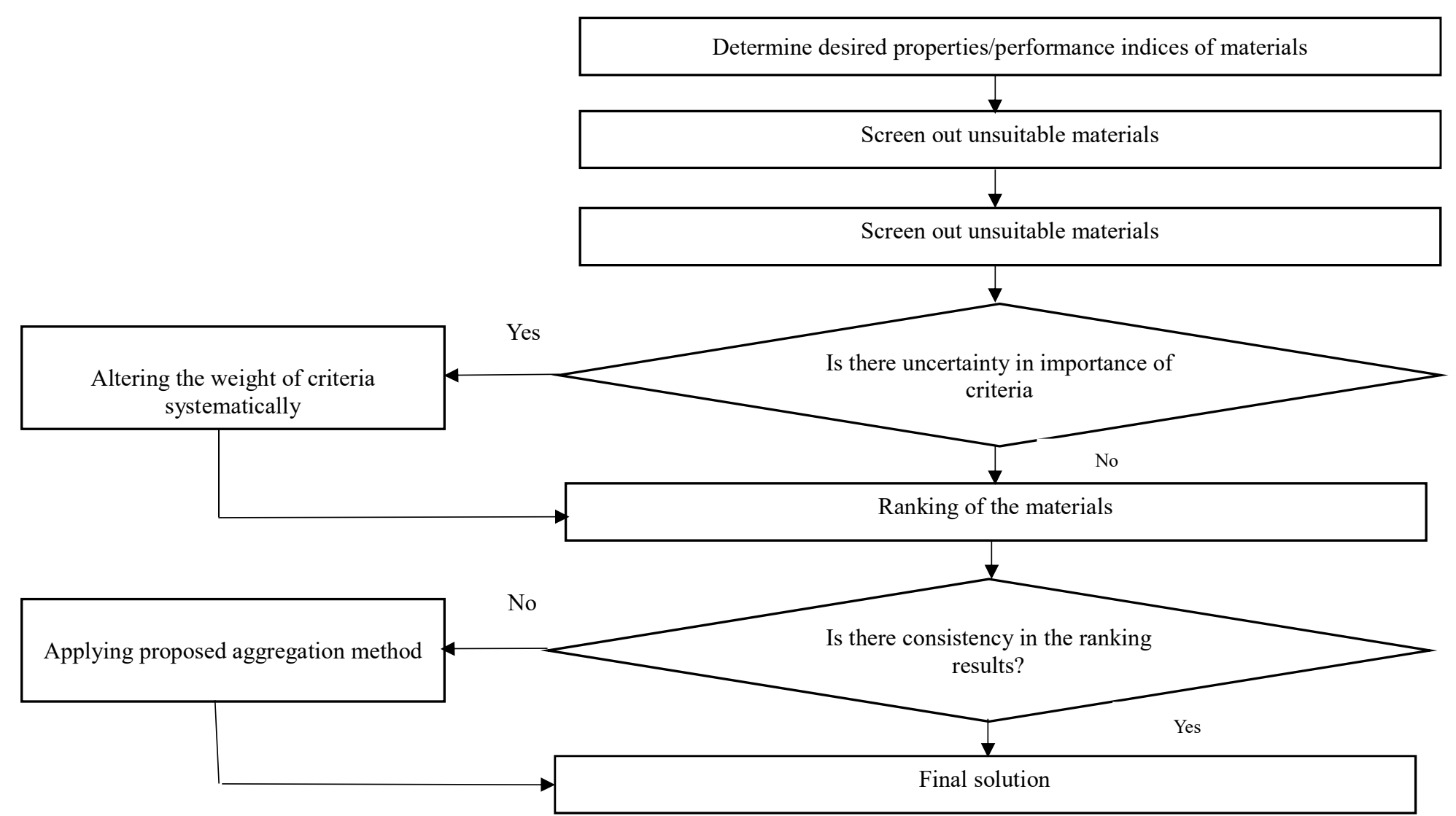

Figure 2. Position of the aggregation technique in the material selection process [23] 


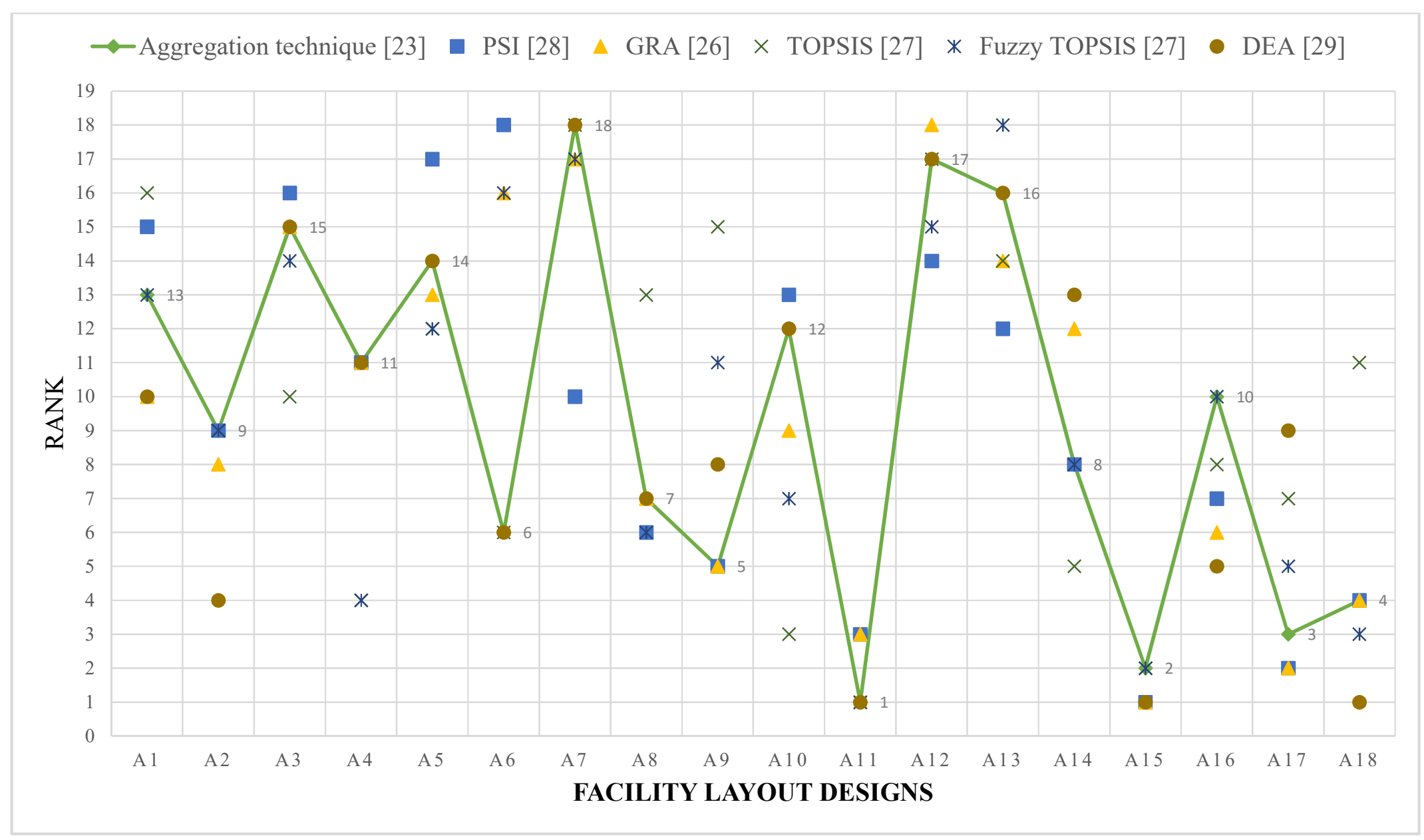

Figure 3. Ranking orders of facility layout design alternatives 


\section{REFERENCES}

[1] Altuntas, S., Selim, H. (2012). "Facility layout using weighted association rule-based data mining algorithms: Evaluation with simulation”. Expert Systems with Applications, 39: 3-13.

[2] Altuntas S., Selim H., Dereli T. (2014). "A fuzzy DEMATEL based solution approach for facility layout problem: A case study". The International Journal of Advanced Manufacturing Technology, 73, 749-771.

[3] Ulutas, B., Islier, A.A. (2015). "Dynamic facility layout problem in footwear industry". Journal of Manufacturing Systems, 36, 55-61.

[4] Ertay, T., Ruan, D., Tuzkaya, U.R. (2006). "Integrating data envelopment analysis and analytic hierarchy for the facility layout design in manufacturing systems". Information Sciences, 176:237-262.

[5] Rajasekharan, M., Peters, B.A., Yang, T. (1998). "A genetic algorithm for facility layout design in flexible manufacturing systems". International Journal of Production Research, 36: 1998.

[6] Islier, A. A. (1998). “A genetic algorithm approach for multiple criteria facility layout design”. International Journal of Production Research, 36: 1549-1569.

[7] Castillo, I., Peters, B.A. (2002). "Unit load and material-handling considerations in facility layout design". International Journal of Production Research, 40: 2955-2989.

[8] Rao, R.V., Singh, D. (2012). "Weighted Euclidean distance based approach as a multiple attribute decision making method for plant or facility layout design selection". International Journal of Industrial Engineering Computations, 3: 365-382.

[9] Altuntas S., Dereli T., Selim H. (2013). "Fuzzy weighted association rule based solution approaches for facility layout problem in cellular manufacturing system" International Journal of Industrial and Systems Engineering, 15, 253-271.

[10] Ulutas, B.H., Kulturel-Konak, S. (2012). “An artificial immune system based algorithm to solve unequal area facility layout problem”. Expert Systems with Applications, 39, 5384-5395.

[11] Ulutaş H. B., İşlier A. A., (2007) A Parameter setting for clonal selection algorithm in facility layout problems, Lecture Notes in Computer Science, 4705, 886-899.

[12] Ulutas, B.H., Kulturel-Konak, S. (2013). “Assessing hypermutation operators of a clonal selection algorithm for the unequal area facility layout problem”. Engineering Optimization, 45, 375-395.

[13] Hadi-Vencheha, A., Mohamadghasemi, A. (2013). "An integrated AHP-NLP methodology for facility layout design". Journal of Manufacturing Systems, 32: 40-45.

[14] Tari, F.G., Neghabi, H. (2015). “A new linear adjacency approach for facility layout problem with unequal area departments". Journal of Manufacturing Systems, 37, 93-103.

[15] Aksarayli, M, Altuntas, S. (2009). "The comparison of layout arrangements for the material flow ordering planning in production systems through simulation analysis”. PAJES 15, 203-214 (In Turkish).

[16] Singh, S.P., Sharma, R. R. K. (2006). "A review of different approaches to the facility layout problems". The International Journal of Advanced Manufacturing Technology, 30, 425-433.

[17] Meller, R., Gau, K. Y. (1996). "The facility layout problem: Recent and emerging trends and perspectives". Journal of Manufacturing Systems, 15, 351-366.

[18] Drira, A., Pierreval, H., Hajri-Gabouj, S. (2007). "Facility layout problems: A survey". Annual Reviews in Control, 31, 255-267.

[19] Farahani, R. Z., Seifi, M. S., Asgari, N. (2010). "Multiple criteria facility location problems: A survey". Applied Mathematical Modelling, 34, 1689-1709.

[20] Canen, A. G., Williamson, G. H. (1998). "Facility layout overview: Towards competitive advantage". Facilities, 16, 198-203.

[21] Snyder, L. V. (2006). "Facility location under uncertainty: A review". IIE Transactions, 38, 537-554.

[22] Current, J., Min, H., Schilling, D. (1990). "Multiobjective analysis of facility location decisions". European Journal of Operational Research, 49, 295-307.

[23] Jahan, A., Ismail, M.Y, Shuib, S., Norfazidah, D., Edwards, K.L. (2011). “An aggregation technique for optimal decision-making in materials selection". Materials and Design, 32: 4918-24. 
[24] Sharma, P.,Singhal, S. (2016). "Design and evaluation of layout alternatives to enhance the performance of industry”. OPSEARCH, 1-20. DOI: 10.1007/s12597-016-0257-6.

[25] Attri, R., Grover, S. (2015). “Application of preference selection index method for decision making over the design stage of production system life cycle”. Journal of King Saud University - Engineering Sciences, 27, 207-216.

[26] Kuo, Y., Yang, T., Huang, G.V. (2008). "The use of grey relational analysis in solving multiple attribute decision-making problems”. Computers \& Industrial Engineering, 55: 80-93.

[27] Yang, T., Hung, C. C. (2007). "Multiple-attribute decision making methods for plant layout design problem”. Robotics and Computer-Integrated Manufacturing 23: 126-137.

[28] Maniya, K.D., Bhat, M.G. (2011). “An alternative multiple attribute decision making methodology for solving optimal facility layout design selection problems”. Computers \& Industrial Engineering 61:542-549.

[29] Yang, T., Kuo, C. (2003). “A hierarchical AHP/DEA methodology for the facilities layout design problem”. European Journal of Operational Research, 147:128-136. 